\title{
Linear Matrix Inequalities in multivariable ship's steering
}

\author{
Monika Rybczak, M. Sc. \\ Gdynia Maritime University
}

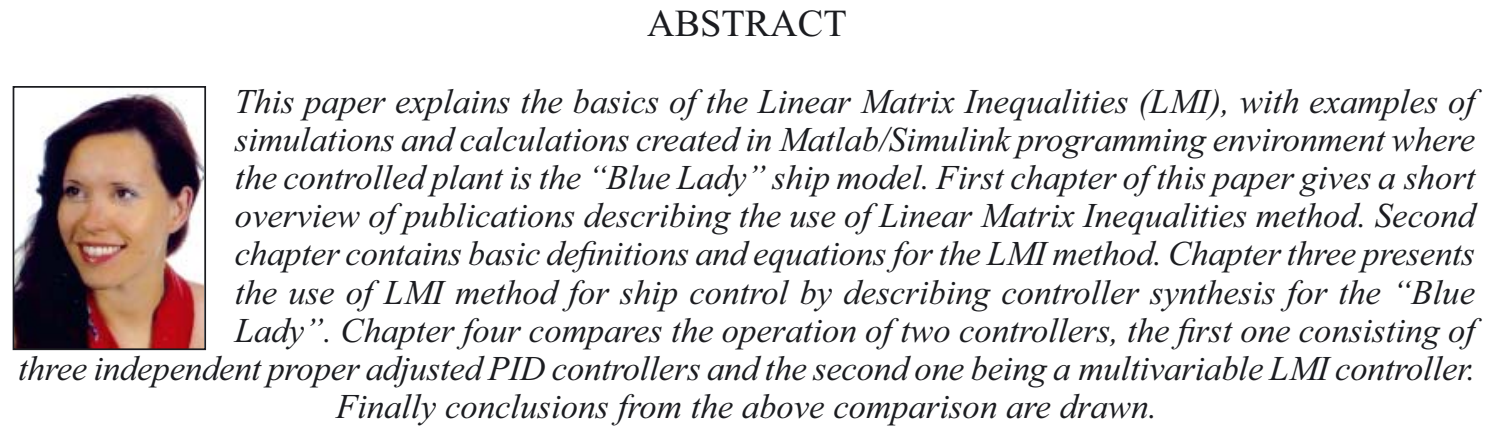

Keywords: linear matrix inequality; use of LMI; synthesis of regulators; multivariable system; ship's control

\section{APPLICATIONS OF THE LMI}

Linear Matrix Inequalities (LMI) methods are used mostly for theoretical numerical calculations. Additionally in the past few years a rising demand for practical use of LMI in science and industrial applications, such as different kinds of complex networks (e.g. power systems, computer networks) and industrial engineering, was observed.

The use of LMI for modelling synchronization problems in complex networks with rapidly changing topology was presented in [1]. Examples of such networks were the Internet and power grids. More specifically the LMI method was used to design a controller used for damping oscillations in a power grid which was described in [2]. The idea was to stop the controller operation when the grid was in a stable state. A controller with such a design could be used both in decentralized and centralized networks. Similar design was described in [3] where a controller was damping oscillations of a synchronous generator connected to a rigid power grid. A related example was also a thyristor controller for a capacitor bank stabilizing a flexible power grid which was described in [4]. A real industrial application was described in [5] where a control system was controlling several steam boilers supplying a decentralized steam consumer network characterized with frequent and large load changes. A similar example was a controller for chemical to electrical energy conversion or more precisely a steam boiler - steam turbine with generator couple. The complexity of the process was caused by the need to parameter steam generation, steam input to the turbine and electrical energy from the generator parameters all at the same time as described in [6]. Another application was a system to control skyscraper movemen 't under extreme wind conditions by the use of an active mass driver. The mass driver was installed on a real building model and was tested in a wind tunnel as described in [7].

The most closely related to marine applications, and thus the most practical use of LMI was the controller of an autonomous underwater vehicle MR-X1 (Marine Robot Experimental 1) built by the Japanese Agency for Marine-Earth Science and Technology (JAMSTEC). The robot was equipped with 5 propellers, it could work in remote control mode or as a fully autonomous unit. Aquarium test trials gave very promising results, a detailed description can be found in [8].

\section{THE PRINCIPLES OF USE OF THE LMI METHOD}

Linear Matrix Inequalities LMI are described by canonical form $[9,10]$ :

$$
F(x)=F_{o}+\sum_{i=1}^{m} x_{i} F_{i}>0
$$

where:

$\mathrm{F}(\mathrm{x}) \quad-$ variable affinic function of the variable $\mathrm{x}$ is a positive definite matrix, $\mathrm{x} \in \mathrm{R}^{\mathrm{m}}$, $\mathrm{F}_{\mathrm{i}} \in \mathrm{R}^{\mathrm{nxn}}$.

$\mathrm{F}_{\mathrm{i}}, \mathrm{i}=0,1 \ldots \mathrm{m}-\mathrm{constant}$ and symmetrical,

$\mathrm{x} \quad-$ the variable (unknown). 
The LMI method is related to the feasibility problem, which comes down to searching for the answer to the question whether there exists a solution $\mathrm{x}$ to the LMI problem in it's overall form shown below:

$$
\mathrm{A}(\mathrm{x})<0
$$

Where a is the state matrix of the control system.

In order to create an LMI for a control system for the object is necessary to check if the eigenvalues of the matrix a of the controlled closed loop system are placed in the left half complex plane.

Next the feasibility problem and stability can be checked with the Laypunov function shown below:

$$
\mathrm{V}(\mathrm{x})=\mathrm{x}^{\mathrm{T}} \mathrm{Px}
$$

Where $\mathrm{P}$ is a positively symmetric matrix.

The stability condition can be formulated with the use of LMI as shown below:

$$
\mathrm{A}^{\mathrm{T}} \mathrm{P}+\mathrm{PA}<0, \mathrm{P}=\mathrm{P}^{\mathrm{T}} \succ 0
$$

Fulfilling the $\mathrm{P}=\mathrm{P}^{\mathrm{T}} \succ 0$ (operand,$\succ$ " means that eigenvalues of matrix $\mathrm{P}$ are positive) condition determines whether the control system is stable and solves the feasibility problem, which is finding a positive definite matrix $\mathrm{P}$ for the given state matrix A. After checking the above conditions dynamic properties of the control system can be designed by pole placement in a specific part of the left half complex plane. A defined plane for pole placement was designated $\mathrm{C}_{\text {stab }}$ [12].

Three exemplary limit areas have been shown below and the first case has been used in simulations described in this paper:

\section{a) First case}

$$
\mathrm{C}_{\text {stab }}=\{\mathrm{s} \in \mathrm{C}|| \mathrm{s}+\mathrm{q} \mid \prec \mathrm{r}\} \Leftrightarrow\left[\begin{array}{cc}
-\mathrm{r} & \mathrm{s}+\mathrm{q} \\
-\mathrm{s}+\mathrm{q} & -\mathrm{r}
\end{array}\right] \prec 0
$$

Where:

$\mathrm{r}-$ radius of the circle,

q - centre of the circle

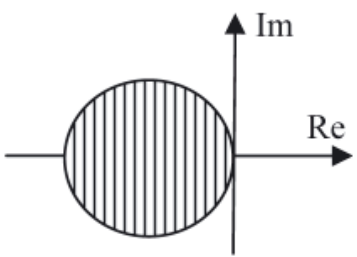

Fig. 1. Left half plane with a circle

b) Second case

$$
\begin{gathered}
\mathrm{C}_{\mathrm{stab}}=\left\{\mathrm{s} \in \mathrm{C} \mid \alpha_{1} \prec \operatorname{Re}(\mathrm{s}) \prec \alpha_{2}\right\} \Leftrightarrow \\
{\left[\begin{array}{cc}
(\mathrm{s}+\overline{\mathrm{s}})-2 \alpha_{2} & 0 \\
0 & -(\mathrm{s}+\overline{\mathrm{s}})+2 \alpha_{1}
\end{array}\right] \prec 0}
\end{gathered}
$$

where:

$\alpha_{1}, \alpha_{2}-$ vertical bars

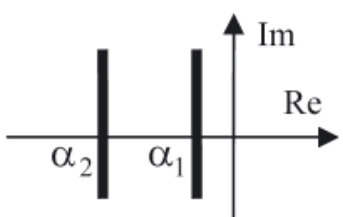

Fig. 2. Left half plane with two vertical bars c) Third case

$$
\begin{gathered}
\mathrm{C}_{\text {stab }}=\{\mathrm{s} \in \mathrm{C}|\operatorname{Re}(\mathrm{s}) \operatorname{tg}(\theta) \prec-| \operatorname{Im}(\mathrm{s}) \mid\} \Leftrightarrow \\
{\left[\begin{array}{cc}
(\mathrm{s}+\overline{\mathrm{s}}) \sin (\theta) & (-\mathrm{s}+\overline{\mathrm{s}}) \cos (\theta) \\
(-\mathrm{s}+\mathrm{s}) \cos (\theta) & (\mathrm{s}+\overline{\mathrm{s}}) \sin (\theta)
\end{array}\right] \prec 0}
\end{gathered}
$$

where:

$\theta \in\left(0, \frac{\pi}{2}\right) \quad$ - angle of flare

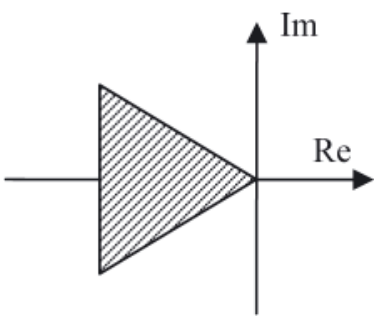

Fig. 3. Left half plane with an angle of flare $\theta$ sector

After pole placement in the left half complex plane a further controller synthesis requires a description according to a defined standard such as $\mathrm{H}_{\infty}$.

A multidimensional control system MIMO (Multiple Input Multiple Output) for controlled system $\mathrm{G}$ is shown in Fig. 4,

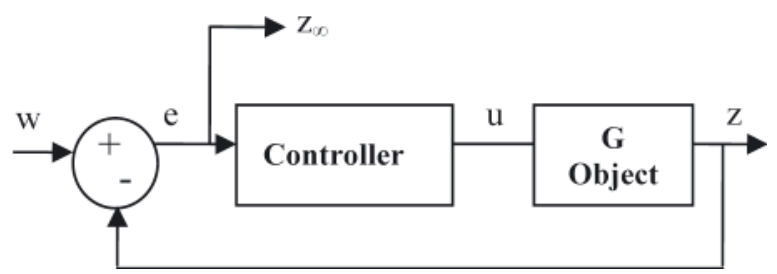

Fig. 4. Structure of a system for tracking set value to synthesize a multivariable regulator

and has the below transfer function:

$$
\mathrm{G}(\mathrm{s})=\frac{\mathrm{Z}(\mathrm{s})}{\mathrm{W}(\mathrm{s})}=\frac{\mathrm{z}(\mathrm{t})}{\mathrm{w}(\mathrm{t})}
$$

where:

Z(s) - Laplace transform of output vector,

$\mathrm{W}(\mathrm{s})$ - Laplace transform of input vector,

$\mathrm{z}(\mathrm{t})$ - output signal vector,

$\mathrm{w}(\mathrm{t}) \quad$ - input signal vector.

Controlled system $G$ described by equation (8) was presented in matrix transfer operator form shown below:

$$
\mathrm{G}=\left[\begin{array}{ll}
\mathrm{A} & \mathrm{B} \\
\mathrm{C} & \mathrm{D}
\end{array}\right]
$$

For which the space state equalities are as follows:

$$
\begin{gathered}
\dot{\mathrm{X}}=\mathrm{Ax}+\mathrm{Bw} \\
\mathrm{z}=\mathrm{Cx}+\mathrm{Dw}
\end{gathered}
$$

where:

A - state matrix with dimensions $\mathrm{n} \times \mathrm{n}$,

$\mathrm{B}$ - input matrix with dimensions $\mathrm{n} \times \mathrm{r}$,

$\mathrm{C}$ - output matrix with dimensions $\mathrm{m} \times \mathrm{n}$,

D - direct feedback matrix with dimensions $\mathrm{m} \times \mathrm{r}$,

$\mathrm{x}$ - state of the system with a vector dimension $\mathrm{n}$,

$\mathrm{w}$ - input signal with a vector dimension $\mathrm{r}$,

$\mathrm{z}$ - output signal, with a vector dimension $\mathrm{m}$, measured by sensors. 
In control theory $[9,16]$ many criteria are used to determine the quality of control. In this paper the $\mathrm{H}_{\infty}$ standard was selected, it determines the relation between input signal vector $\mathrm{w}(\mathrm{t})$ and output signal vector $\mathrm{z}(\mathrm{t})$ for $\mathrm{G}$ controlled system (see Fig. 4):

$$
\|\mathrm{G}(\mathrm{s})\|_{\infty}=\sup _{\omega \in \mathrm{R}} \sigma_{\max }[\mathrm{G}(\mathrm{j} \omega)]
$$

Where $\sigma_{\max }(Z)$ is the highest singular value of matrix $A$, which is equivalent to a square root of the highest eigenvalue of the matrix $\mathrm{A}^{\mathrm{T}} \mathrm{A}$. In numerical calculations the upper limit value of $\mathrm{H}_{\infty}$ was called scalar variable gamma $\gamma$.

The $\mathrm{H}_{\infty}$ standard for $\mathrm{G}$ system matrix is lesser than the scalar variable gamma $\gamma[12,16]$ if, and only if $\gamma^{2} \mathrm{I}-\mathrm{D}^{\mathrm{T}}>0$ and there exists a matrix $\mathrm{P}=\mathrm{P}^{\mathrm{T}} \succ 0$ that fulfils the linear matrix inequality shown below:

$$
\begin{gathered}
\left(\mathrm{A}^{\mathrm{T}} \mathrm{P}+\mathrm{PA}+\mathrm{C}^{\mathrm{T}} \mathrm{C}\right)+\left(\mathrm{PB}+\mathrm{C}^{\mathrm{T}} \mathrm{D}\right) \\
\left(\gamma^{2} \mathrm{I}-\mathrm{D}^{\mathrm{T}} \mathrm{D}\right)-1\left(\mathrm{~B}^{\mathrm{T}} \mathrm{P}+\mathrm{D}^{\mathrm{T}} \mathrm{C}\right) \prec 0
\end{gathered}
$$

After calculations, the value of variable gamma is an approximation of the upper limit of the $\mathrm{H}_{\infty}$ standard. During controller synthesis there are two possibilities, the $\mathrm{H}_{\infty}$ can be minimalized or can be a restriction if gamma is set to be a constant value. In this paper gamma, by means of trial and error, was set to be a constant value of 1.5.

After using Schur's complement to linear matrix inequality (12) we received the $\mathrm{H}_{\infty}$ standard in the form of an LMI requirement:

$$
\left[\begin{array}{cc}
A^{T} P+P A+C^{T} C & P B+C^{T} D \\
B^{T} P+D^{T} C & D^{T} D-\gamma^{2} I
\end{array}\right] \prec 0
$$

If we assume that the transmittance $\mathrm{T}_{\mathrm{w} \rightarrow \mathrm{zo}}(\mathrm{s})$ describes the control system deviation transmittance, where $z_{\infty}$ is defined as $\mathrm{z}_{\infty}=\mathrm{w}-\mathrm{z}$ (see Fig. 4) then the minimalization of the standard of the defined transmittance tends to assume the smallest value for all frequencies.

\section{CASE STUDY}

\section{a) Controlled system description}

The training ship "Blue Lady" is a 1:24 scale model of a VLCC (Very Large Crude Carrier) tanker that was meant to carry large amounts of crude oil but unfortunately was never built.

Main propulsion is a d.c. electric motor driving a five blade, fixed pitch, propeller through a reduction gear [15]. The propulsion characteristic corresponds to turbine propulsion but it has an option to be changed to diesel engine propulsion. The model is also equipped with two tunnel thrusters and two side thrusters simulating 60 ton tug boats. „Blue Lady’s” cockpit has enough space for two people. The silhouette of the ship is shown below.

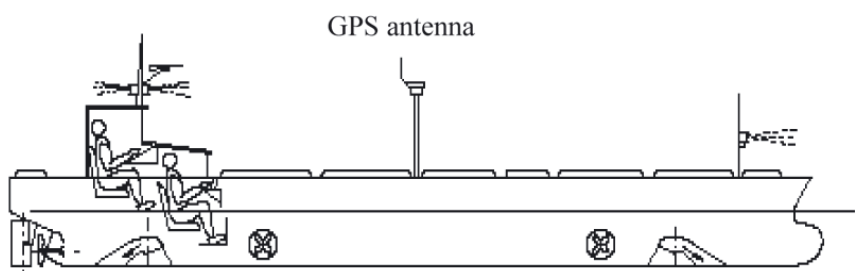

Fig. 5. Silhouette of "Blue Lady" with cockpit arrangement and GPS antenna
Tab. 1. "Blue Lady" model and real ship parameter comparison

\begin{tabular}{|c|c|c|}
\hline & Ship & Model \\
\hline Overall lenght & $330.65[\mathrm{~m}]$ & $13.78[\mathrm{~m}]$ \\
\hline Breadth & $57.00[\mathrm{~m}]$ & $2.38[\mathrm{~m}]$ \\
\hline Maximum speed & $28150[\mathrm{~m} / \mathrm{h}]$ & $5741.2[\mathrm{~m} / \mathrm{h}]$ \\
\hline
\end{tabular}

Training ship "Blue Lady", being the controlled system in the considered case, had three input signals $\left[\tau_{x} \tau_{y} \tau_{p}\right]$ (see Fig. 6) where:

$\tau_{\mathrm{x}}-$ required force (thrust) in the ships longitudinal axis,

$\tau_{y}-$ required force (thrust) in the ships lateral axis,

$\tau_{\mathrm{p}}-$ required turning moment.

Taking into consideration the number and type of propellers eight command signals for propulsion and steering equipment were implemented [ngc $\delta \mathrm{c} \operatorname{sstd}_{\mathrm{c}} \operatorname{sstr}_{\mathrm{c}} \operatorname{ssod}_{\mathrm{c}} \alpha_{\mathrm{dc}} \operatorname{ssor}_{\mathrm{c}} \alpha_{\mathrm{rc}}$ ] (see Fig. 6).

Where:

$\left[\mathrm{X}_{\mathrm{I}} \mathrm{Y}_{\mathrm{I}} \mathrm{N}_{\mathrm{I}}\right]$ - were forces and moments created by propulsion and steering equipment, and the three output signals were position coordinates $\mathrm{x}(\mathrm{t}), \mathrm{y}(\mathrm{t})$ and the heading $\psi(\mathrm{t})$.

For future controller synthesis with the LMI method the state model aspect had to be determined. Considering input and output signals of the future controller for the "Blue Lady" model the following were taken into account: dynamics and kinematics of the ship, Kalman's filter, geographic coordinates and a system for recalculating command signals to particular thrusters. It should be noted that dynamic equations of the ship had the following form (so called 3DOF model):

$$
\begin{gathered}
\mathrm{m}(\dot{\mathrm{u}}-\mathrm{rv})=\mathrm{X}_{\mathrm{I}}[\mathrm{N}] \\
\mathrm{m}(\dot{\mathrm{v}}-\mathrm{ru})=\mathrm{Y}_{\mathrm{I}}[\mathrm{N}] \\
\mathrm{I}_{\mathrm{Z}} \dot{\mathrm{r}}=\mathrm{N}_{\mathrm{I}}[\mathrm{N}]
\end{gathered}
$$

Where:

m - ship's displacement,

$\mathrm{u}$ - linear velocity in respect to $\mathrm{X}$ axis,

$\mathrm{V}$ - linear velocity in respect to $\mathrm{Y}$ axis,

$\mathrm{r} \quad-$ angular velocity around $\mathrm{Z}$ axis.

Whereas course changes and ships position which were the kinematic equations had been calculated from the below formula:

$$
\begin{gathered}
\psi(\mathrm{t})=\psi_{0}\left(\mathrm{t}_{0}\right)+\int_{\mathrm{t}_{0}}^{\mathrm{t}} \mathrm{r}(\tau) \mathrm{d} \tau \\
\mathrm{x}(\mathrm{t})=\mathrm{x}_{0}\left(\mathrm{t}_{0}\right)+\int_{\mathrm{t}_{0}}^{\mathrm{t}}[\mathrm{u}(\tau) \cos (\psi(\tau))-\mathrm{v}(\tau) \sin (\psi(\tau))] \mathrm{d} \tau \\
\mathrm{y}(\mathrm{t})=\mathrm{y}_{0}\left(\mathrm{t}_{0}\right)+\int_{\mathrm{t}_{0}}^{\mathrm{t}}[\mathrm{u}(\tau) \sin (\psi(\tau))+\mathrm{v}(\tau) \cos (\psi(\tau))] \mathrm{d} \tau
\end{gathered}
$$

A block diagram of the controlled system has been presented on Fig. 6.

\section{b) Linear model of the controlled object}

It turned out, during identification process, that three signal channels demonstrated weak correlation between output and input signals: 


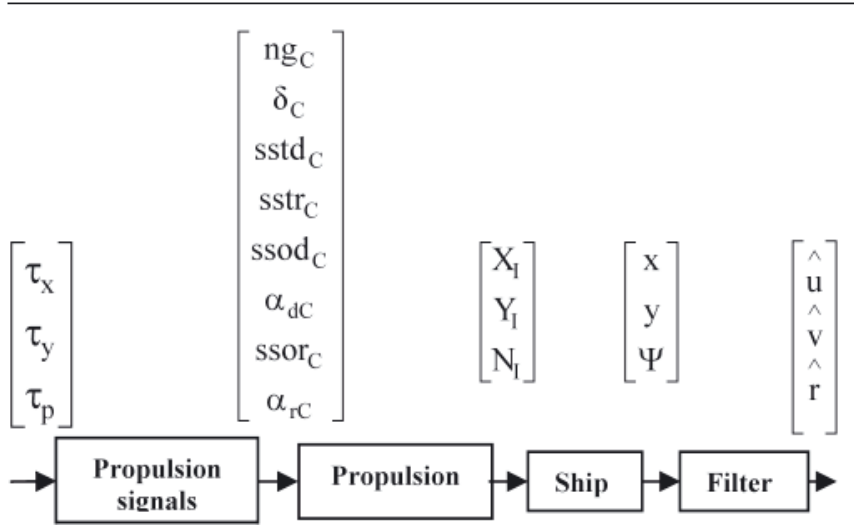

Fig. 6. Block diagram of the controlled system for identification process. $\boldsymbol{u}, \boldsymbol{v}, \boldsymbol{r}$-ships velocities; $\boldsymbol{x}, \boldsymbol{y}, \boldsymbol{\psi}$-ships position and course, $\left[\boldsymbol{n g}_{\boldsymbol{c}}, \boldsymbol{\delta}_{\boldsymbol{c}} \ldots\right] \boldsymbol{T}$ vectors - command signals for propulsion and steering equipment, $\left[X_{I} Y_{I} N_{I}\right] T$ vectors - forces

and moments generated by propulsion and steering equipment

$$
\tau_{\mathrm{x}} \rightarrow \hat{\mathrm{v}}, \tau_{\mathrm{y}} \rightarrow \hat{\mathrm{u}}, \tau_{\mathrm{p}} \rightarrow \hat{\mathrm{r}}
$$

therefore these subsystems were canceled from the final model (see Fig. 7):

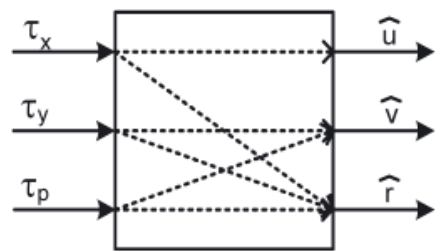

Fig. 7. Control channels after identification process

Finally the multivariable linear state model of the system had the following form:

$$
\begin{gathered}
{\left[\begin{array}{l}
\dot{x}_{1} \\
\dot{x}_{2} \\
\dot{x}_{3}
\end{array}\right]=\left[\begin{array}{ccc}
a_{\mathrm{uu}} & 0 & 0 \\
0 & \mathrm{a}_{\mathrm{vv}} & \mathrm{a}_{\mathrm{rv}} \\
\mathrm{a}_{\mathrm{ur}} & \mathrm{a}_{\mathrm{vr}} & \mathrm{a}_{\mathrm{rr}}
\end{array}\right] *\left[\begin{array}{l}
\mathrm{x}_{1} \\
\mathrm{x}_{2} \\
\mathrm{x}_{3}
\end{array}\right]+} \\
+\left[\begin{array}{ccc}
\mathrm{b}_{\mathrm{uu}} & 0 & 0 \\
0 & \mathrm{~b}_{\mathrm{vv}} & \mathrm{b}_{\mathrm{rv}} \\
\mathrm{b}_{\mathrm{ur}} & \mathrm{b}_{\mathrm{vr}} & \mathrm{b}_{\mathrm{rr}}
\end{array}\right] *\left[\begin{array}{l}
\tau_{\mathrm{x}} \\
\tau_{\mathrm{y}} \\
\tau_{\mathrm{p}}
\end{array}\right] \\
{\left[\begin{array}{l}
\mathrm{u} \\
\mathrm{v} \\
\mathrm{r}
\end{array}\right]=\left[\begin{array}{lll}
1 & 0 & 0 \\
0 & 1 & 0 \\
0 & 0 & 1
\end{array}\right] *\left[\begin{array}{l}
\mathrm{x}_{1} \\
\mathrm{x}_{2} \\
\mathrm{x}_{3}
\end{array}\right]}
\end{gathered}
$$

where 0 values denoted cancelled channels.

The coefficient values of the model parameters were obtained as average values from all identification experiments. State model coefficients were as follows [11]:

Tab. 2. Values of "Blue Lady" model coefficients in state space

\begin{tabular}{|c|c|c|c|}
\hline parameter & value & parameter & value \\
\hline $\mathrm{a}_{\mathrm{uu}}$ & $-3.36 * 10^{-3}$ & $\mathrm{~b}_{\mathrm{uu}}$ & $3.62 * 10^{-3}$ \\
\hline $\mathrm{a}_{\mathrm{vv}}$ & $-9.00 * 10^{-3}$ & $\mathrm{~b}_{\mathrm{vv}}$ & $2.06 * 10^{-3}$ \\
\hline $\mathrm{a}_{\mathrm{rv}}$ & $-2.00 * 10^{-4}$ & $\mathrm{~b}_{\mathrm{rv}}$ & $1.61 * 10^{-5}$ \\
\hline $\mathrm{a}_{\mathrm{ur}}$ & $-3.00 * 10^{-3}$ & $\mathrm{~b}_{\mathrm{ur}}$ & $3.00 * 10^{-5}$ \\
\hline $\mathrm{a}_{\mathrm{vr}}$ & $-1.00 * 10^{-3}$ & $\mathrm{~b}_{\mathrm{vr}}$ & $1.15 * 10^{-5}$ \\
\hline $\mathrm{a}_{\mathrm{rr}}$ & $-7.75 * 10^{-3}$ & $\mathrm{~b}_{\mathrm{rr}}$ & $7,00 * 10^{-3}$ \\
\hline
\end{tabular}

\section{c) Controller synthesis}

The first condition for the LMI method applied to the feasibility problem (2) and required checking if the eigenvalues of the system matrix were placed in the left half complex plane. For the state matrix of the simulated system a that had the below form:

$$
A=\left[\begin{array}{ccc}
a_{u u} & 0 & 0 \\
0 & a_{v v} & a_{r v} \\
a_{u r} & a_{v r} & a_{r r}
\end{array}\right]
$$

Next the stability had to be checked, which came down to fulfilling the Laypunov inequality (4) which meant that for the given state matrix a you looked for a positively determined symmetric matrix $\mathrm{P}=\mathrm{P}^{\mathrm{T}} \succ 0[9,12,13]$.

For the state matrix of the simulated controller a symmetric matrix $\mathrm{P}$ was found, and had the following values:

$$
\mathrm{P}=\left[\begin{array}{ccc}
2.0658 & 0.0119 & 0.1021 \\
0.0119 & 1.9766 & -0.0044 \\
0.1021 & -0.0044 & 1.9034
\end{array}\right]
$$

After describing LMI conditions from the theoretical part of the article with matrix form, a multivariable controller was designed for a MIMO system, the described "Blue Lady" ship model. First step was to determine the matrices based on system structure (see Fig. 4) and system description (22). Below a system of equations for the controlled system has been presented together with output equations defining signals for $\mathrm{H}_{\infty}$ standard, measured signal from system to controller "e" and output signal " $\mathrm{z}$ ".

$$
\left[\begin{array}{c}
\mathrm{z}_{\infty} \\
\mathrm{z} \\
\mathrm{e}
\end{array}\right]=\left[\begin{array}{ccc}
\mathrm{A} & \mathrm{B}_{\mathrm{u}} & \mathrm{B}_{\mathrm{w}} \\
\mathrm{C}_{\infty} & \mathrm{D}_{\infty \mathrm{u}} & \mathrm{D}_{\infty \mathrm{w}} \\
\mathrm{C}_{\mathrm{z}} & \mathrm{D}_{\mathrm{zu}} & \mathrm{D}_{\mathrm{zw}} \\
\mathrm{C}_{\mathrm{e}} & \mathrm{D}_{\mathrm{eu}} & \mathrm{D}_{\mathrm{ew}}
\end{array}\right] *\left[\begin{array}{c}
\mathrm{u} \\
\mathrm{w}
\end{array}\right]
$$

LMI matrices had the following form:

$$
\begin{aligned}
& \dot{x}=A x+B_{u} u+B_{w} w \\
& z_{\infty}=C_{\infty} x+D_{\infty u} u+D_{\infty w} w \\
& z=C_{z} x+D_{z u} u+D_{z w} w \\
& e=C_{e} x+D_{e u} u+D_{e w} w
\end{aligned}
$$

where the matrices representing input signals "w" and "u" were vector matrices $[3 \mathrm{x} 1]$ because they applied to $\left[\tau_{\mathrm{x}}, \tau_{\mathrm{y}}, \tau_{\mathrm{p}}\right]$ signals. Additionally vector matrices for output signals " $\mathrm{z}$ " and " $z_{\infty}$ " were also [3x1] and they applied to: longitudinal " $u$ ", lateral "v" and rotational " $\mathrm{r}$ " velocity signals.

After checking that the controlled system fulfilled the feasibility condition (2) and stability condition (4) its dynamic properties had to be specified by pole placement in the left half complex plane $[12,14]$. In this paper limit area (5) was used.

For the input and calculation of the above parameters with the LMI method the LMI Control Toolbox in Matlab together with additional toolboxes SeDuMi (Self - Dual - Minimization) and YALMIP (Yet Another LMI Preprocessor) was used $[18,19]$. 


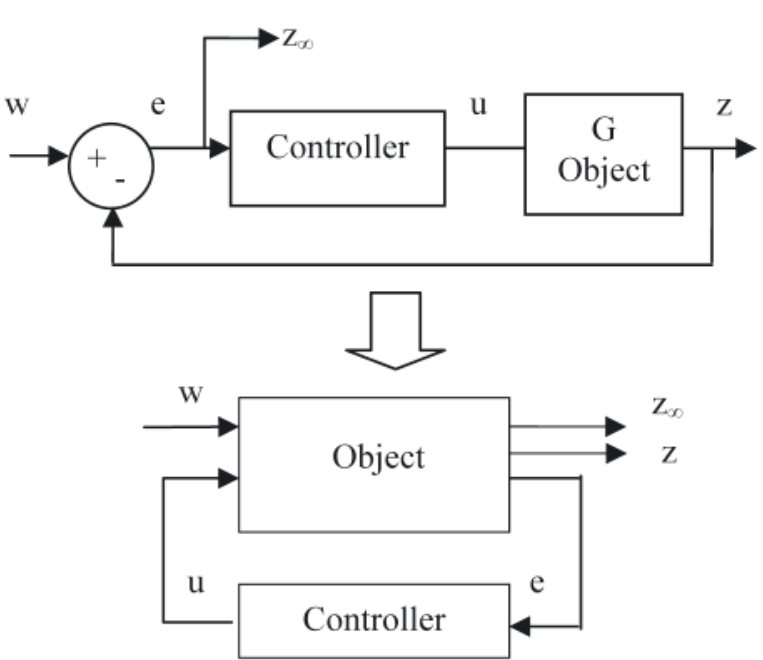

Fig. 8. Up side is the structure of a system for tracking set value, down side is the standard structure using the LMI method to synthesize a multivariable controller where the object is "Blue Lady" ship model

Experimentally selected parameters of the limit area had the following values (see Fig. 1):

- radius of the circle -0.04

- centre of the circle -0.02

For controller synthesis, after determining the limit area, additional evaluation of the $\mathrm{H}_{\infty}$ standard was done, for which the scalar variable " $\gamma$ " was the estimated upper limit value.

After using Schur's complement and making some modifications to the controlled system described by (24) and based on (13) the following $\mathrm{H}_{\infty}$ standard condition for LMI method was received:

$$
\begin{aligned}
& {\left[\mathrm{AR}+\mathrm{RA}^{\mathrm{T}}+\mathrm{B}_{\mathrm{u}} \mathrm{C}_{\mathrm{x}}+\mathrm{C}_{\mathrm{x}}^{\mathrm{T}} \mathrm{B}_{\mathrm{u}}^{\mathrm{T}} \quad \mathrm{A}_{\mathrm{x}}^{\mathrm{T}}+\mathrm{A}+\mathrm{B}_{\mathrm{u}} \mathrm{D}_{\mathrm{x}} \mathrm{C}_{\mathrm{e}}\right.} \\
& A_{x}+A^{T}+C_{e}^{T} D_{x}^{T} B_{u}^{T} \quad A^{T} S+S A+B_{x} C_{e}+C_{e}^{T} B_{x}^{T} \\
& \mathrm{~B}_{\mathrm{w}}^{\mathrm{T}}+\mathrm{D}_{\mathrm{ew}}^{\mathrm{T}} \mathrm{D}_{\mathrm{x}}^{\mathrm{T}} \mathrm{B}_{\mathrm{u}}^{\mathrm{T}} \quad \mathrm{B}_{\mathrm{w}}^{\mathrm{T}} \mathrm{S}+\mathrm{D}_{\mathrm{ew}}^{\mathrm{T}} \mathrm{B}_{\mathrm{x}}^{\mathrm{T}} \\
& \mathrm{C}_{\infty} \mathrm{R}+\mathrm{D}_{\text {cou }} \mathrm{C}_{\mathrm{x}} \quad \mathrm{C}_{\infty}+\mathrm{D}_{\text {cou }} \mathrm{D}_{\mathrm{x}} \mathrm{C}_{\mathrm{e}} \\
& \mathrm{B}_{\mathrm{w}}+\mathrm{B}_{\mathrm{u}} \mathrm{D}_{\mathrm{x}} \mathrm{D} \quad \mathrm{RC}_{\infty}^{\mathrm{T}}+\mathrm{C}_{\mathrm{x}}^{\mathrm{T}} \mathrm{D}_{\infty \mathrm{u}} \\
& \mathrm{SB}_{\mathrm{w}}+\mathrm{B}_{\mathrm{x}} \mathrm{D}_{\mathrm{ew}} \quad \mathrm{C}_{\infty}^{\mathrm{T}}+\mathrm{C}_{\mathrm{e}}^{\mathrm{T}} \mathrm{D}_{\mathrm{x}}^{\mathrm{T}} \mathrm{D}_{\infty \mathrm{u}}^{\mathrm{T}}
\end{aligned}
$$

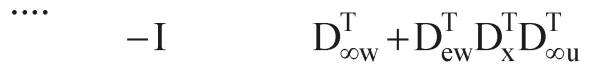

$$
\begin{aligned}
& \mathrm{D}_{\text {cow }}+\mathrm{D}_{\text {cal }} \mathrm{D}_{\mathrm{x}} \mathrm{D}_{\mathrm{ew}} \\
& -\gamma^{2}
\end{aligned}
$$

In the above matrix inequality new matrices $\mathrm{R}$ and $\mathrm{S}$ were used. They were calculated by congruence transformation of LMI conditions which was true for the below equations of a closed loop circuit:

$$
\begin{aligned}
& \mathrm{D}_{\mathrm{x}}=\mathrm{D}_{\mathrm{k}} \\
& \mathrm{C}_{\mathrm{x}}=\mathrm{C}_{\mathrm{k}} \mathrm{M}^{\mathrm{T}}+\mathrm{D}_{\mathrm{k}} \mathrm{C}_{\mathrm{e}} \mathrm{R} \\
& \mathrm{B}_{\mathrm{x}}=\mathrm{NB}_{\mathrm{k}}+\mathrm{SB}_{\mathrm{u}} \mathrm{D}_{\mathrm{k}} \\
& \mathrm{A}_{\mathrm{x}}=\mathrm{NA}_{\mathrm{k}} \mathrm{M}^{\mathrm{T}}+\mathrm{NB}_{\mathrm{k}} \mathrm{C}_{\mathrm{e}} \mathrm{R}+\mathrm{SB}_{\mathrm{u}} \mathrm{C}_{\mathrm{k}} \mathrm{M}^{\mathrm{T}}+\mathrm{S}\left(\mathrm{A}+\mathrm{B}_{\mathrm{u}} \mathrm{D}_{\mathrm{k}} \mathrm{C}_{\mathrm{e}}\right) \mathrm{R}
\end{aligned}
$$

Above equations contained $\mathrm{N}$ and $\mathrm{M}$ matrices which were connected to Laypunov variable factorization of matrix $\mathrm{X}$ related to LMI conditions describing $\mathrm{H}_{\infty}$ standard together with pole placement limit area, as described in $[9,12,16]$.

For the simulations in this paper $\mathrm{H}_{\infty}$ was calculated to be: 1.08 , for a constant upper limit value of the scalar variable " $\gamma$ " equal to: 1.5. After calculating LMI method conditions the matrices for the designed controller were following:

$$
\begin{gathered}
\mathrm{Ak}=\left[\begin{array}{cccccc}
-0.0276 & 0.0019 & -0.0001 & 0.0031 & 0.0178 & 0.0708 \\
0.0024 & -0.0301 & 0.0015 & -0.0072 & -0.0424 & 0.0098 \\
-0.0001 & 0.0016 & -0.0196 & 0.0291 & -0.0041 & -0.0007 \\
0.0007 & 0.0010 & -0.0058 & -0.0277 & -0.0035 & 0.0005 \\
0.0030 & 0.0077 & 0.0014 & -0.0031 & -0.0426 & 0.0014 \\
-0.0014 & -0.0047 & 0.0001 & 0.0007 & 0.0022 & -0.0490
\end{array}\right] \\
\mathrm{Bk}=\left[\begin{array}{cccc}
-0.0143 & 0.0000 & 0.0010 \\
0.0045 & -0.0014 & 0.0153 \\
-0.0003 & -0.0226 & -0.0010 \\
0.0040 & 0.0623 & 0.0225 \\
0.0211 & -0.0181 & 0.0999 \\
0.0855 & 0.0020 & -0.0517
\end{array}\right]
\end{gathered}
$$

$$
\mathrm{Ck}=\left[\begin{array}{cccccc}
-0.3026 & 0.0489 & -0.0035 & 0.0552 & 0.3187 & 1.1398 \\
0.0003 & -0.0141 & -0.2773 & 0.8015 & -0.2311 & 0.0231 \\
0.0193 & 0.3300 & -0.0301 & 0.1415 & 0.6626 & -0.4161
\end{array}\right]
$$

$$
\mathrm{Dk}=\left[\begin{array}{ccc}
0 & 0 & 0 \\
0 & 0 & 0 \\
0 & 0 & 0
\end{array}\right]
$$

\section{SIMULATION RESULTS}

For the simulations in this paper basic assumptions have been analyzed. Fig. 9 below shows changes made to the structure of the system from Fig. 8

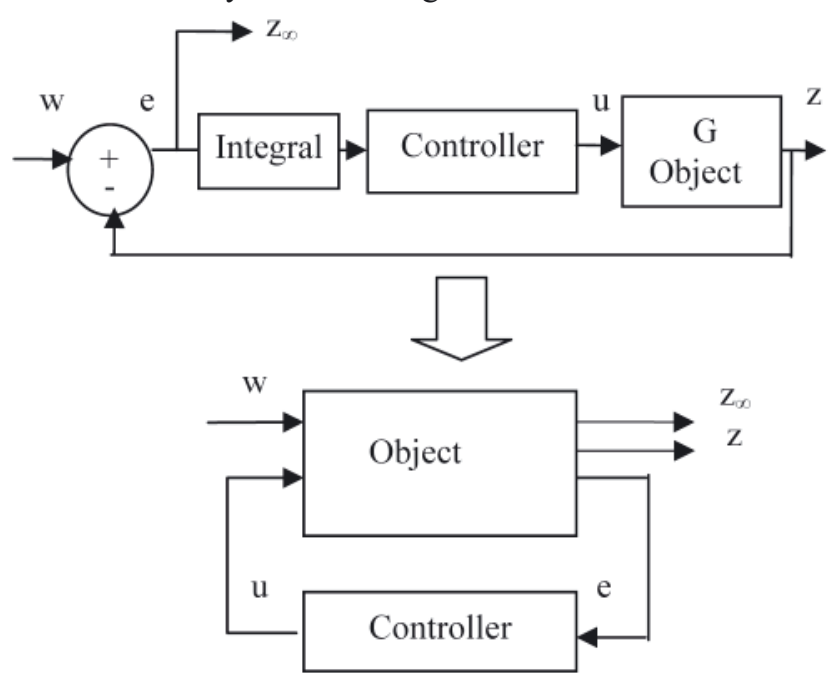

Fig. 9. Upper is the structure of a system for tracking set value with dynamic and kinematic parameters, lower is the standard structure using the LMI method to synthesize a multivariable regulator where the system is "Blue Lady" ship model

The practical aim was to realize "Blue Lady" ship model steering for three velocities. In the simulations a multidimensional LMI controller designed by the author was compared with a controller consisting of three independent PID controllers designed by an M.Sc. graduate of Maritime Academy in Gdynia, as described in his paper [17]. Simulation results were achieved in Matlab with YALMIP and SeDuMi toolboxes and had parameters from the table 3 . 
Tab. 3. simulation parameters

\begin{tabular}{|c|c|c|c|}
\hline \multicolumn{4}{|c|}{ Simulations with one velocity } \\
\hline simulation no. & $\begin{array}{l}\text { longitudinal } \\
\text { velocity } \\
{[\mathbf{m} / \mathbf{s}]}\end{array}$ & $\begin{array}{c}\text { lateral } \\
\text { velocity } \\
{[\mathbf{m} / \mathbf{s}]}\end{array}$ & $\begin{array}{c}\text { rotational } \\
\text { velocity } \\
{[\mathrm{rad} / \mathrm{s}]}\end{array}$ \\
\hline I & 0.2 & 0 & 0 \\
\hline II & -0.2 i 0.2 & 0 & 0 \\
\hline \multicolumn{4}{|c|}{ Simulations with two velocities } \\
\hline simulation no. & $\begin{array}{c}\text { Iongitudinal } \\
\text { velocity } \\
{[\mathbf{m} / \mathbf{s}]} \\
\end{array}$ & $\begin{array}{c}\text { lateral } \\
\text { velocity } \\
{[\mathbf{m} / \mathbf{s}]} \\
\end{array}$ & $\begin{array}{c}\text { rotational } \\
\text { velocity } \\
{[\mathrm{rad} / \mathrm{s}]}\end{array}$ \\
\hline III & 0.2 & 0.08 & 0 \\
\hline IV & -0.2 i 0.2 & -0.08 i 0.08 & 0 \\
\hline \multicolumn{4}{|c|}{ Simulations with three velocities } \\
\hline simulation no. & $\begin{array}{c}\text { Iongitudinal } \\
\text { velocity } \\
{[\mathbf{m} / \mathbf{s}]} \\
\end{array}$ & $\begin{array}{l}\text { lateral } \\
\text { velocity } \\
{[\mathrm{m} / \mathrm{s}]} \\
\end{array}$ & $\begin{array}{c}\text { rotational } \\
\text { velocity } \\
{[\mathrm{rad} / \mathrm{s}]}\end{array}$ \\
\hline $\mathrm{V}$ & 0.2 & 0.08 & 0.1 \\
\hline VI & -0.2 i 0.2 & -0.08 i 0.08 & -0.1 i 0.1 \\
\hline
\end{tabular}

Every simulation was started from $\psi_{0}=0$ [deg].

In order to determine the quality of control the following formula was used:

$$
\Delta \mathrm{x}^{2}=\frac{1}{\mathrm{n}} \sum_{1}^{\mathrm{n}}\left(\mathrm{x}-\mathrm{x}_{\mathrm{re}}\right)^{2}
$$

where:

$\mathrm{n}$ - number of measurements,

$\mathrm{x}$ - reference signal value,

$\mathrm{x}_{\mathrm{re}}-$ output signal value received from the system.

a) Simulations for one velocity, with a given value of longitudinal velocity $u=0.2[\mathrm{~m} / \mathrm{s}]$
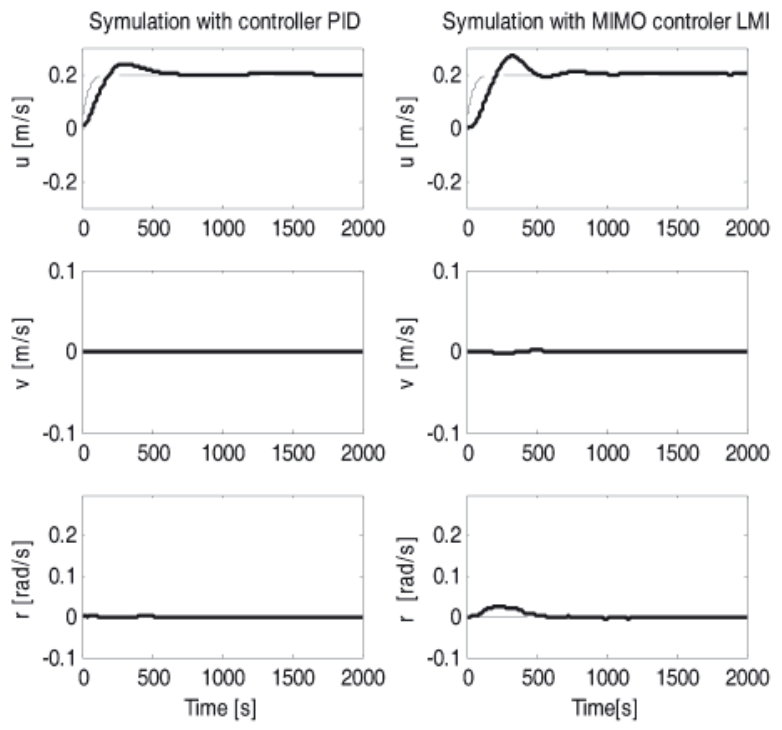

Fig. 10. Graphs for three components of sideways movement. Solid line received velocity, dashed line - given velocity. Left side - PID controller, right side LMI controller simulation results

Tab. 4. Comparison of average value deviations from given velocities

\begin{tabular}{|c|c|c|}
\hline Velocity & $\begin{array}{c}\text { for PID } \\
\text { controller }\end{array}$ & $\begin{array}{c}\text { for LMI } \\
\text { controller }\end{array}$ \\
\hline longitudinal $-\mathbf{u ~}[\mathbf{m} / \mathbf{s}]$ & 0.0004433 & 0.0009162 \\
\hline lateral $-\mathbf{v}[\mathbf{m} / \mathbf{s}]$ & 0.0000000 & 0.0000010 \\
\hline rotational $-\mathbf{r}[\mathbf{r a d} / \mathbf{s}]$ & 0.0000004 & 0.0000501 \\
\hline
\end{tabular}

\section{Comment:}

For the LMI controller the average deviation value from given longitudinal velocity was twice as big as for the PID controller. Settling time for the received velocity was comparable for both controllers. Unfortunately the average deviation value from given rotational velocity was significantly higher for the LMI controller than for the PID controller.

b) Simulations for two velocities, with given values of longitudinal velocity $u=0.2[\mathrm{~m} / \mathrm{s}]$ and lateral velocity $\mathrm{v}=\mathbf{0 . 0 8}[\mathrm{m} / \mathrm{s}]$
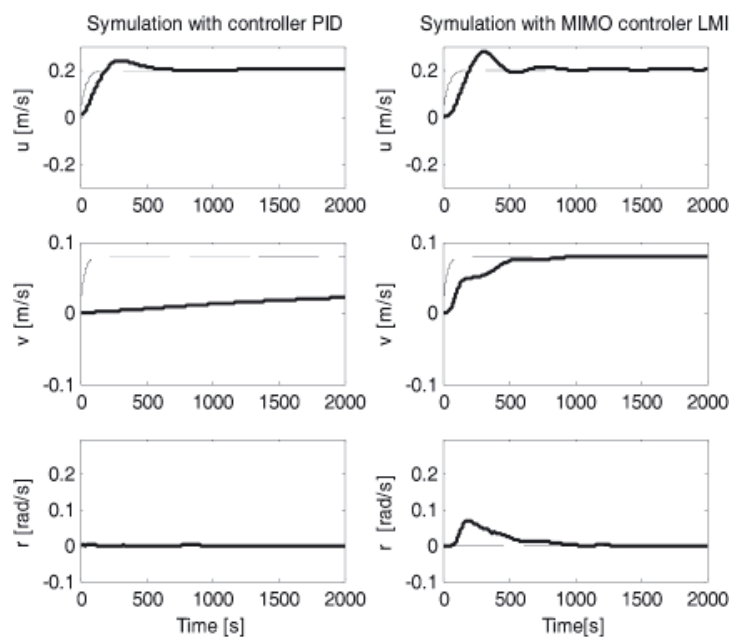

Fig. 11. Graphs for three components of sideways movement. Solid line - received velocity, dashed line - given velocity. Left side - PID controller, right side LMI controller simulation results.

Tab. 5. Comparison of average value deviations from given velocities

\begin{tabular}{|c|c|c|}
\hline Velocity & $\begin{array}{c}\text { for PID } \\
\text { controller }\end{array}$ & $\begin{array}{c}\text { for LMI } \\
\text { controller }\end{array}$ \\
\hline longitudinal $-\mathbf{u ~}[\mathbf{m} / \mathbf{s}]$ & 0.0004 & 0.0010 \\
\hline lateral $-\mathbf{v}[\mathbf{m} / \mathbf{s}]$ & 0.0033 & 0.0002 \\
\hline rotational $-\mathbf{r}[\mathbf{r a d} / \mathbf{s}]$ & 0.0000 & 0.0004 \\
\hline
\end{tabular}

Comment:

Average deviation value from given lateral velocity for the PID controller was unacceptable since the settling time was significantly higher than 2000 [s]. The deviation factor for lateral velocity was more than 30 times smaller for the LMI controller than for the PID controller. The remaining deviations for both controllers were considered standard and acceptable.

c) Simulations for three velocities, with given values of longitudinal velocity $u=0.2[\mathrm{~m} / \mathrm{s}]$, lateral velocity $\mathbf{v}=\mathbf{0 . 0 8}[\mathrm{m} / \mathrm{s}]$ and rotational velocity $\mathbf{r}=0.1[\mathrm{rad} / \mathrm{s}]$

Tab. 6. Comparison of average value deviations from given velocities

\begin{tabular}{|c|c|c|}
\hline Velocity & $\begin{array}{c}\text { for PID } \\
\text { controller }\end{array}$ & $\begin{array}{c}\text { for LMI } \\
\text { controller }\end{array}$ \\
\hline longitudinal $-\mathbf{u ~}[\mathbf{m} / \mathbf{s}]$ & 0.0004 & 0.0010 \\
\hline lateral $-\mathbf{v}[\mathbf{m} / \mathbf{s}]$ & 0.0041 & 0.0002 \\
\hline rotational $-\mathbf{r}[\mathbf{r a d} / \mathbf{s}]$ & 0.0001 & 0.0002 \\
\hline
\end{tabular}

Comment:

Comparing both controllers for this case the LMI controller had better parameters. Lateral velocity settling time was significantly shorter (approx. 1000 [s]) compared to PID controller (more than 2000 [s]). Deviation factor for lateral velocity was almost 40 times smaller for the LMI controller than 
for the PID controller. For longitudinal and rotational velocities both controllers had comparable parameters.
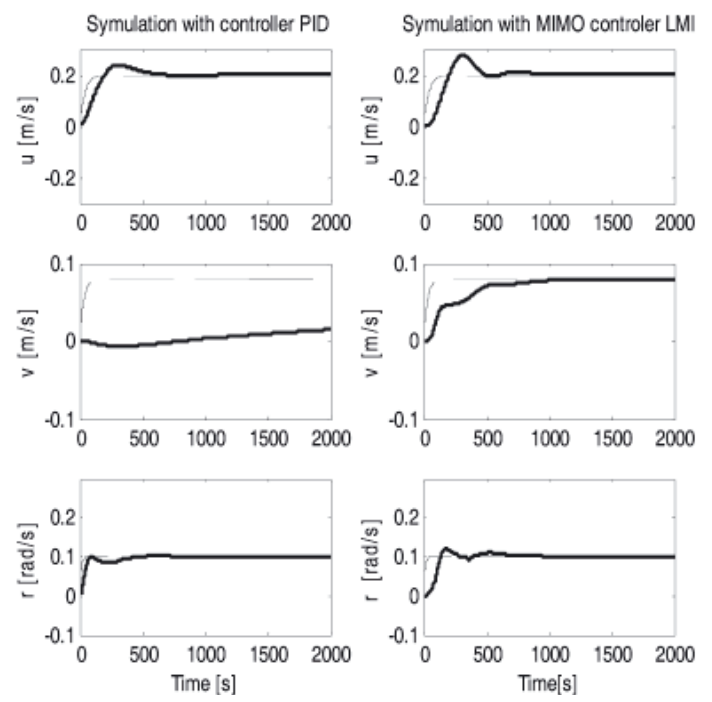

Fig. 12. Graphs for three components of sideways movement. Solid line - received velocity, dashed line - given velocity. Left side-PID controller, right side LMI controller simulation results

d) Simulations for one velocity, with a given value of longitudinal velocity alternating between $u=0.2[\mathrm{~m} / \mathrm{s}]$ and $u=-0.2[\mathrm{~m} / \mathrm{s}]$ in time instant equal to $0[\mathrm{~s}], 600[\mathrm{~s}]$, $1100[s]$ and 1600 [s]
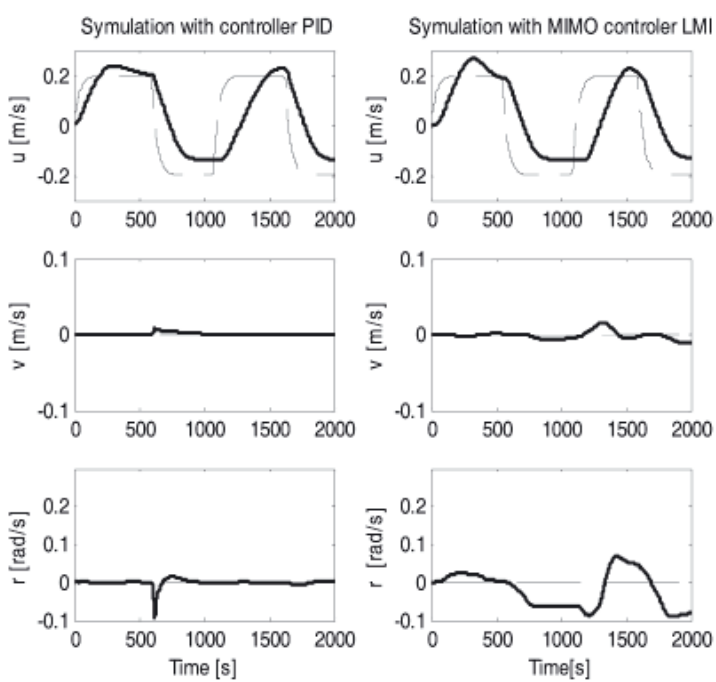

Fig. 13. Graphs for three components of sideways movement. Solid line - received velocity, dashed line - given velocity. Left side - PID controller, right side LMI controller simulation results.

Tab. 7. Comparison of average value deviations from given velocities

\begin{tabular}{|c|c|c|}
\hline Velocity & $\begin{array}{c}\text { for PID } \\
\text { controller }\end{array}$ & $\begin{array}{c}\text { for LMI } \\
\text { controller }\end{array}$ \\
\hline longitudinal $-\mathbf{u ~}[\mathbf{m} / \mathbf{s}]$ & 0.0124 & 0.0152 \\
\hline lateral $-\mathbf{v}[\mathbf{m} / \mathbf{s}]$ & 0.0000 & 0.0000 \\
\hline rotational $-\mathbf{r}[\mathbf{r a d} / \mathbf{s}]$ & 0.0001 & 0.0019 \\
\hline
\end{tabular}

Comment:

Above simulations presented both controllers with given longitudinal velocity changes during the simulation. Average deviation value from given longitudinal velocity was similar for both controllers. The LMI controller however had worse results for given zero velocities, there have been some interference in the system. e) Simulations for two velocities, with given values of longitudinal velocity alternating between $u=0.2[\mathrm{~m} / \mathrm{s}]$ and $u=-0.2[\mathrm{~m} / \mathrm{s}]$ and lateral velocity alternating between $v=0.08[\mathrm{~m} / \mathrm{s}]$ and $\mathrm{v}=\mathbf{- 0 . 0 8}[\mathrm{m} / \mathrm{s}]$ in time instant equal to 0 [s], $600[s], 1100$ [s] and 1600 [s]
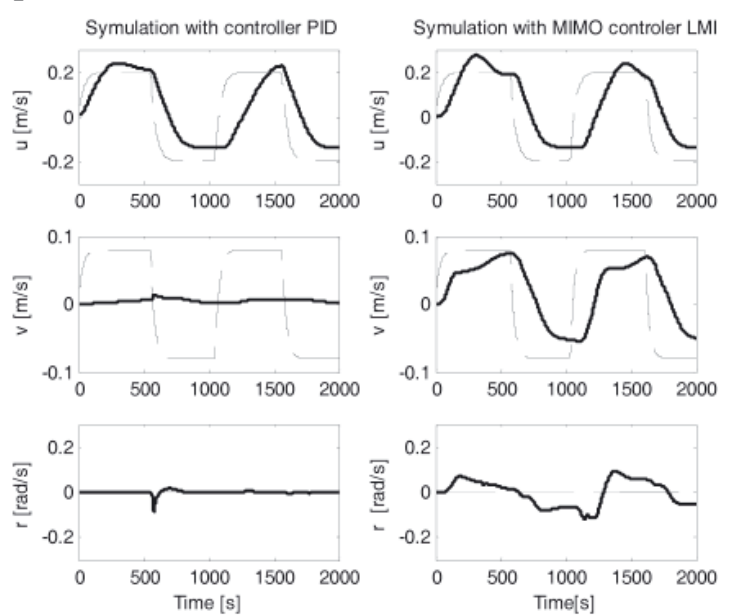

Fig. 14. Graphs for three components of sideways movement. Solid line - received velocity, dashed line - given velocity. Left side - PID controller, right side LMI controller simulation results

Tab. 8. Comparison of average value deviations from given velocities

\begin{tabular}{|c|c|c|}
\hline Velocity & $\begin{array}{c}\text { for PID } \\
\text { controller }\end{array}$ & $\begin{array}{c}\text { for LMI } \\
\text { controller }\end{array}$ \\
\hline longitudinal $-\mathbf{u ~}[\mathbf{m} / \mathbf{s}]$ & 0.0127 & 0.0133 \\
\hline lateral $-\mathbf{v}[\mathbf{m} / \mathbf{s}]$ & 0.0041 & 0.0030 \\
\hline rotational $-\mathbf{r}[\mathbf{r a d} / \mathbf{s}]$ & 0.0001 & 0.0024 \\
\hline
\end{tabular}

Comment:

In the above case both controllers were presented with given longitudinal and lateral velocity changes during the simulation. Looking at settling times and average deviation values from given velocities the LMI controller had worse results than in the previous case but they were still satisfactory as for this stage of the design.

f) Simulations for three velocities, with given values of longitudinal velocity alternating between $u=0.2[\mathrm{~m} / \mathrm{s}]$ and $u=-0.2[\mathrm{~m} / \mathrm{s}]$, lateral velocity alternating between $v=0.08[\mathrm{~m} / \mathrm{s}]$ and $\mathrm{v}=\mathbf{0 . 0 8}[\mathrm{m} / \mathrm{s}]$ and rotational velocity alternating between $r=0.2[\mathrm{rad} / \mathrm{s}]$ and $\mathrm{r}=\mathbf{- 0 . 2}[\mathrm{rad} / \mathrm{s}]$ in time instant equal to 0 [s], 600 [s], 1100 [s] and 1600 [s]
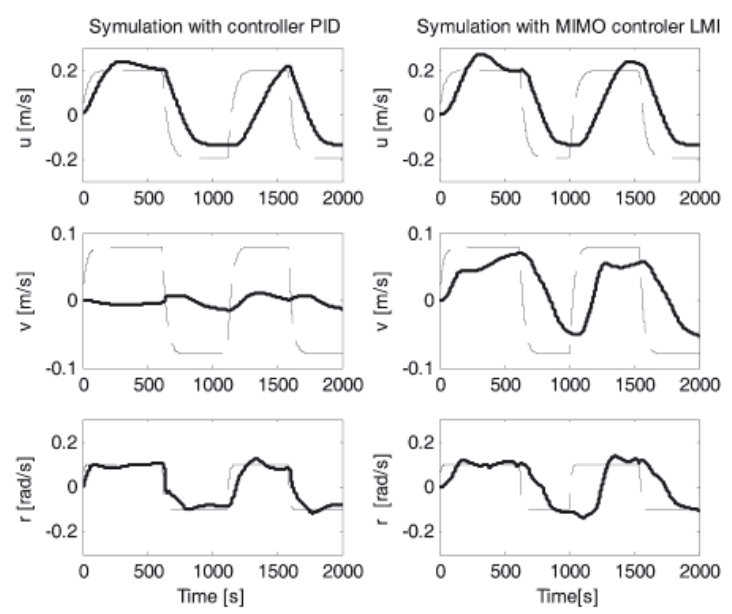

Fig. 15. Graphs for three components of sideways movement. Solid line - received velocity, dashed line-given velocity. Left side-PID controller, right side LMI controller simulation results 
Tab. 9. Comparison of average value deviations from given velocities

\begin{tabular}{|c|c|c|}
\hline Velocity & $\begin{array}{c}\text { for PID } \\
\text { controller }\end{array}$ & $\begin{array}{c}\text { for LMI } \\
\text { controller }\end{array}$ \\
\hline longitudinal $-\mathbf{u ~}[\mathbf{m} / \mathbf{s}]$ & 0.0125 & 0.0153 \\
\hline lateral $-\mathbf{v}[\mathbf{m} / \mathbf{s}]$ & 0.0040 & 0.0031 \\
\hline rotational $-\mathbf{r}[\mathbf{r a d} / \mathbf{s}]$ & 0.0011 & 0.0076 \\
\hline
\end{tabular}

Comment:

In the above simulations both controllers were presented with given longitudinal, lateral and rotational velocity changes during the simulation. Best results for the LMI controller were obtained for deviation values from given lateral velocity, for the other two velocities the PID controller presented better results. The LMI controller however, had better settling times than the PID controller. In the LMI controller, despite having a worse result for rotational velocity, the settling time was not affected as much as the settling time for lateral velocity in the PID controller.

\section{CONCLUSIONS}

This paper was based on results of simulations for a "Blue Lady" ship model trajectory simulator created in Matlab/ Simulink. For LMI calculations to be possible additional Yalmip and SeDuMi toolboxes had to be installed into Matlab libraries. Above simulations have proven that both the LMI and PID controllers have different proprieties. In order for the correct controller to be selected the brief foredesigns have to be taken into consideration. If the important factor would be the output signal settling time than the LMI controller would be the better choice. Despite having different average value deviations from given signals the LMI controller was more resistant to interference during the simulations. Furthermore the LMI controller was of the sixth stage and the control was multidimensional. In future studies external interference will be added to the system to allow further study of the controller.

\section{BIBLIOGRAPHY}

1. Liu T., Zhao J.: Synchronization of complex switched delay dynamical networks with simultaneously diagonalizable coupling matrices. Journal of Control Theory Apel, Vol. 6, No 4, 2008, p. 351-356

2. Bretas: Decentralized output feedback controller design for the damping of electromechanical oscillations. Electrical Power and Energy Systems 26, 2004, p. 207-219

3. Seog-Joo K., Soonman K., Young-Hyun M. : Low-order Robust Power System Stabilizer for Single-machine Systems: An LMI Approach. International Journal of Control, Vol 8, No 3, 2010 p. 556-563
4. Ishimaru M., Yokoyama R., Shirai G., Niimura T.: Robust thyristor - controlled series capacitor controller design based on linear matrix inequality for a multi-machine power system. Electrical Power and Energy Systems 24, 2002, p.621-629

5. Swarnakar A., Marquez H. J., Chen T.: a design framework for overlapping controllers and its industrial application. Control Engineering Practice 17, 2009, p.97-111

6. Wu J., Nguang S. K., Shen J., Liu G., Li Y.G.: Robust $H_{\infty}$ tracking control of boiler-turbine systems. ISA Transactions 49 , 2010, p.: 369-375

7. Lu L. T., Chiang W.-L., Tang J.-P., Liu M.-Y., Chen Ch.-W.: Active control for a benchmark building dunder wind excitation. Journal of Wind Engineering and Industrial Aerodynamics, 91, 2003, p.:469-493

8. Nasuno Y., Shimizu E., Ito M., Yamamoto I., Tsukioka S., Yoshida H., Hyakudome T., Ishibashi S., Aoki T.: Design method for a new control system for an autonomous underwater vehicle using linear matrix inequalities. Artif Life Robotics, 11, 2007, p.:149-152

9. Boyd S., EL Ghaoui L., Feron E., Balakrishnan V.: Linear Matrix in System and Control Theory. SIAM, Philadelphia, 1994

10.Balas G.J., Doyle J.C. Glover K., Packard A. and Smith R.: Analysis and Synthesis Toolbox. Ver.4, The Mathworks Inc., Natick, USA, 2001

11. Gierusz W.: Simulation model of the shiphandling training boat „Blue Lady”, Int. IFAC Conference Control Applications in Marine Systems CAMS'01, Glasgow, Scotland, 2001

12.Koziński W.: Controller design. Chosen classical and optimization methods., PW, Warszawa, 2004. (in Polish)

13.Kaczorek T. : Vectors and matrices in automation and electrotechnics., WNT, Warszawa, 1998 (in Polish)

14.Rybczak M., Gierusz W.: Linear Matrix Inequalities in multivariable ship's steering, Polish Journal of Environmental Studies, Gdynia 2010, p.:100-106

15. Rybczak M: The use of VRML program language to simulate ship model's movement environment. Gdynia, 2006 (in Polish)

16.Scherer C., Wieland S.: Linear Matrix Inequalities in Control. Delft University of Technology, 2004

17. Sirocki S.: Multidimensional ship's control with the use of PID controllers. Gdynia, 2009 (In Polish)

18.http://sedumi.ie.lehigh.edu/

19.http://users.isy.liu.se/johanl/yalmip/

\section{CONTACT WITH THE AUTHOR}

Monika Rybczak, M.Sc.

Faculty of Marine Electrical Engineering, Gdynia Maritime University, Morska 81-87

81-225 Gdynia, POLAND e-mail: mrybczak@am.gdynia.pl 